\title{
Coping strategies used by the elderly regarding aging and death: an integrative review
}

\author{
Mariana dos Santos Ribeiro' \\ Moema da Silva Borges ${ }^{2}$ \\ Tereza Cristina Cavalcanti Ferreira de Araúi $0^{3}$ \\ Mariana Cristina dos Santos Souza'
}

\section{Abstract}

Objective: to identify and synthesize studies that approach the coping strategies used by the elderly to deal with aging and death. Method: an integrative review was performed in seven databases with the following descriptors: psychological adaptation, the elderly, death and aging. Results: 73 articles were identified. After applying the inclusion and exclusion criteria, six articles that identified multiple losses experienced by the elderly and included coping strategies were selected and analyzed. The main losses were: loss of health; physical capacity and functionality; loss in quality of emotional relationships; death of loved ones; reduced social integration; fewer material goods; financial loss; lower cognitive resources; lower perceived mastery; loss of feeling useful; reduction in subjective well-being and quality of life. We also identified the following coping strategies

Keywords: Adaptation Psychological. Elderly. Death. Aging. used to deal with losses related to aging and finitude: anticipated grieving; wish to die isolation; submission; negotiation; acceptance; accommodation; support seeking; living in the moment; seeking spiritual comfort. Conclusion: the elderly experience aging and finitude with coping strategies that can generate both unfavorable and favorable health outcomes. In this context, some coped through anticipated mourning and the desire to die, while others looked for spiritual comfort, social support and acceptance.

\footnotetext{
Universidade de Brasília, Programa de Pós Graduação em Enfermagem. Brasília, DF, Brasil.

2 Universidade de Brasília, Departamento de Enfermagem. Brasília, DF, Brasil.

Universidade de Brasília, Departamento de Psicologia Clínica. Brasília, DF, Brasil.
} 


\section{INTRODUCTION}

Understanding death and old age depends on cultural definitions. Culture is extremely important for gerontology, as the way in which a society defines concepts such as the person, age and life course varies greatly depending on the cultural context in which it is inserted ${ }^{1}$.

Despite the different cultural understandings of each culture, however, aging is a phase of life permeated by multiple losses. There is the loss of youth, sometimes accompanied by the loss of health and independence. Without denying the virtues and wisdom that accompany aging, we must recognize that for most people this process is not easy ${ }^{2}$.

From this perspective, it can be said that aging represents an accumulation of successive losses throughout life that include physical limitations, illness, retirement and other losses that are characterized as symbolic deaths ${ }^{3}$.

The meaning of death is not only present at the end of life, but pervades the process of human development and is present in daily life. It can be said that the more we live, the more we risk losing something or someone important, and that this fact can generate stress due to being out of our control ${ }^{3}$.

In this context, stressful situations can be classified into two categories: traumatic events, or in other words external situations or people who present themselves as a threat to the wellbeing of an individual; and uncontrollable events, which are situations that challenge the limits of our capacities and our concepts of ourselves, such as death and aging ${ }^{4}$.

Stress and coping are therefore closely related concepts; stress is not only a response to the physiological and emotional reactions of the body but is understood as the result of the interaction between the individual and the environment ${ }^{4,5}$.

Such coping consists of the individual effort required to handle stressful problems and emotions that affect the psychological and physical results of a destabilizing situation. It is a multidimensional, dynamic process that raises a number of responses and encompasses the individual's interaction with their environment, using mechanisms to manage an impending threat and difficult life situations ${ }^{4,6}$.

Coping for elderly persons is different from coping for people of other age groups, as stressors also change with age. While young adults experience more stress in areas related to work, their finances, home maintenance, their personal life, family, and friends; the elderly tend to experience stress related to the limitations of aging 1 .

Stress among the young is therefore more related to the roles they play, while stress among the elderly occurs due to reduced skills arising from aging ${ }^{1}$.

As we age, we begin to use our past coping experiences as a guide to dealing with the stressful situations of the present ${ }^{1}$.

This review therefore aims to identify and synthesize studies that deal with coping strategies used by elderly people to deal with aging and death.

\section{METHOD}

An integrative review was carried out in a systematic and orderly manner, based on six steps: 1) the creation of a guiding question that defines which articles should be included, 2) a search of scientific literature which should be broad enough to answering the guiding question, 3) the collecting of the data of the selected articles using a previously elaborated instrument to extract the necessary information, 4) critical analysis of the included articles, considering the methodological rigor and the characteristics of each study, 5) discussion of results with other articles 6) presentation of the review in a clear and objective manner?

To support the development of the study, the following guiding question was created: what coping strategies are used by elderly people when faced with aging and death? From this question, the following search descriptors were defined: psychological adaptation, elderly, death and aging.

The descriptor "psychological adaptation" was chosen because it encompasses the concept of 
confrontation as defined by the Health Sciences Descriptors, while the descriptor "death" had the purpose of representing finitude and symbolic deaths, that is, losses over the course of life. The descriptors "elderly" and "aging", meanwhile, were chosen to delimit the study population.

The descriptors were grouped using the Boolean operator AND in the following databases: Latin American and Caribbean Literature in Health Sciences (LILACS), the Nursing Database (BDENF), Medical Literature Analysis and Retrieval System Online (MEDLINE), US National Library of Medicine (PUBMED) and American Psychological Association (APA), Cumulative Index of Nursing and Allied Health Literature (CINAHL) and Scopus.

The search was performed in June 2016 and the following inclusion criteria were adopted: original articles published in Portuguese, English and Spanish from January 2010 to June 2016, available online and in full text format. The exclusion criteria were: repeated articles, sample of elderly persons with dementia, sample of relatives and articles that did not address the theme of psychological adaptation and death.

After the selection of the articles, the information was organized in a framework with the objective of evaluating the methodological rigor and characteristics of each study. After being subjected to a critical analysis, the information was discussed with other authors in order to better elucidate the subject, and finally, the conclusions of the review were elaborated and presented.

\section{RESULTS}

A total of 73 articles were identified, of which six were selected for analysis (figure 1).

The six articles selected were from South America, North America, Europe and Asia, with one study carried out in Brazil. The objectives of the articles addressed the research question and the methodologies used were qualitative, quantitative and mixed (Chart 1).

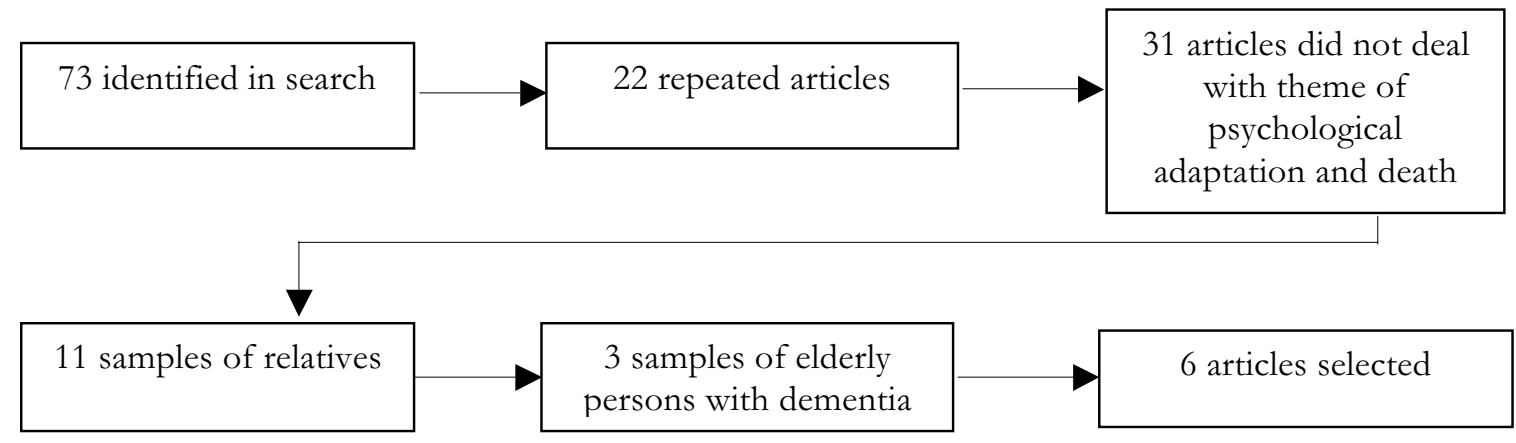

Figure 1. Selection process of articles in Lilacs, Medline, Bdenf, Pubmed, Apa, Cinahl and Scopus databases. Brasília, Distrito Federal, 2016. 
Chart 1. Synthesis of articles selected by author, journal, year, location, objective and method. Brasília, Distrito Federal, 2016.

\begin{tabular}{|l|l|l|}
\hline Authors & Journal, location and year & Objective and method \\
\hline $\begin{array}{l}\text { Ho AH, Chan CL, Leung PP, } \\
\text { Rhochinov HM, Neimeyer } \\
\text { RA, Pang SM, et al. }\end{array}$ & $\begin{array}{l}\text { Age and Ageing } \\
\text { (China, 2013). }\end{array}$ & $\begin{array}{l}\text { Examine the concept of living and dying with dignity } \\
\text { in a Chinese context and explore the generality of the } \\
\text { model of dignity for terminally ill elderly persons in } \\
\text { Hong Kong. Qualitative. }\end{array}$ \\
\hline $\begin{array}{l}\text { Maxfield M, Pyszczynski T, } \\
\text { Greenberg J, Pepin R, Davis }\end{array}$ & $\begin{array}{l}\text { Psychology and Aging } \\
\text { (USA, 2012). }\end{array}$ & $\begin{array}{l}\text { Test the hypothesis that the greater the executive } \\
\text { functioning of an elderly person, the greater the } \\
\text { tolerance for reminders of death. Quantitative. }\end{array}$ \\
\hline $\begin{array}{l}\text { Dockendorff DCT. } \\
\text { Palgi Y, Shrira A, Ben-Ezra } \\
\text { M, Spalter T, Shmotkin D, } \\
\text { Kavé G. }\end{array}$ & $\begin{array}{l}\text { Educational Gerontology } \\
\text { (Chile, 2014). }\end{array}$ & $\begin{array}{l}\text { Report healthy ways of dealing with the losses related } \\
\text { to the aging process. Mixed Method. }\end{array}$ \\
\hline $\begin{array}{l}\text { Giacomin KC, Santos WJ, 2010). } \\
\text { Firmo JOA. }\end{array}$ & $\begin{array}{l}\text { Ciência \& Saúde Coletiva } \\
\text { (Science and Collective } \\
\text { Health) (Brazil, 2013). }\end{array}$ & $\begin{array}{l}\text { To investigate whether several indicators of subjective } \\
\text { well-being and subjective health decline with the } \\
\text { approach of death and which of these shows a greater } \\
\text { decline. Quantitative. }\end{array}$ \\
$\begin{array}{l}\text { To understand anticipated mourning, perceived in the } \\
\text { interaction between old age and the health-disease and } \\
\text { incapacity processes, in the views of the elderly when } \\
\text { faced with their own finitude. Qualitative. }\end{array}$ \\
\hline $\begin{array}{l}\text { Rurup ML, Deeg DJ, } \\
\text { Onwuteaka-Philipsen BD. }\end{array}$
\end{tabular}

The selected articles addressed two main themes: a) symbolic deaths, that is, the losses experienced by elderly people due to the aging process; and b) the coping strategies used to deal with these and with finitude.

The main losses were: loss of health and/or physical capacity; loss of functionality; loss of quality of emotional relationships; death of loved ones; reduced social integration; reduction of material assets; financial loss; reduction of cognition; loss of feeling of mastery; loss of feeling of being useful, reduction of subjective well-being and quality of life.

The main coping strategies were: anticipatory mourning, the desire to die, isolation, submission, negotiation, acceptance, accommodation, seeking social support, seeking spiritual comfort and living in the moment.

\section{DISCUSSION}

The connection between the health professional and the patient is an essential element of the quality of care provided ${ }^{8}$. For this reason, it is important to understand each person on an individual basis, considering how they experience losses and the coping strategies they use when faced with numerous adverse situations.

In this context, the present discussion is structured based on the two main results found: losses and coping.

\section{Losses}

In order to understand the losses experienced by elderly people, a study conducted in Chile carried out thirty-six semi-structured interviews with individuals aged over 65 years and listed the following losses: a) loss of health and/or physical capacity; b) loss of quality in emotional relationships; c) the death of loved ones; d) reduced social integration; e) reduction of quality of life in a material sense; $f$ ) reduction of the quality of life in a cognitive sense?

The physical limitations relating to aging and illness were the most commonly reported losses 
among the elderly. Losses in health and/or physical ability are evidenced as: a decline in psychomotor ability, sensory losses, a reduced perception of strength and energy, and sexual difficulties?.

When faced with losses, mainly related to physical limitations, the elderly person may fear becoming dependent and being a burden on family members ${ }^{10}$. A longitudinal study conducted in New Zealand which accompanied the transition from independence to dependency and death of twenty-five elderly patients with severe heart disease confirmed that participants reported experiencing fear of becoming dependent on their partners, friends and family ${ }^{11}$.

Physical limitations with lower levels of independence were also a relevant theme in a study in China that sought to explore the generality of the model of dignity for the elderly. While some points were different in the Chinese context, however, physical limitations with a loss of independence and functional limitations with negative implications on quality of life were similar to the Western context ${ }^{12}$.

A study carried out in the Netherlands with 31 elderly persons who had experienced the desire to die at some point in their life showed that dependence generated a loss of the feeling of mastery in many elderly people; the subjects reported that people decided for them and interfered in decision-making in daily life, leading to a reduction in their freedom. It can be said that the elderly persons no longer felt able to control their problems or their own lives ${ }^{13}$.

It was perceived that dependence due to physical limitations is a cross-sectional theme found in several countries, including in the Western context. While old age brings with it a sense of approaching death, the greatest fear for the elderly is dependence, not death itself. It is important to consider that the losses experienced by these individuals are not only physical, but also emotional and social ${ }^{9,10}$.

The loss of quality in emotional relationships refers to the negative perception of important changes in the affective relationships associated with aging. A weakening of emotional bonds was noted, and it was felt that while people are physically present, they can be emotionally absent ${ }^{9}$.
The death of loved ones is demonstrated by the loss of significant persons. Widowhood is the most common and also one of the most affecting of such deaths, although the deaths of friends and relatives should also be considered ${ }^{9,10}$. In this case, loneliness is a frequent theme and is interpreted as a reduction in one's social support network, since the feeling is aggravated when the person who died was close to the elderly person ${ }^{13}$.

In this context, widowhood overburdens old age with the effects of continuous solitude. One loses one's companion of many years and of a life built for two, leaving a feeling of emptiness. Associated with the loss of affection with widowhood are losses of the guarantee of social and family status, the security of the bond, the sense of tranquility of having someone to grow old with, economic stability and the comforting sensation of having someone who can be counted on ${ }^{2}$.

Reduced social integration is another loss noted in the reports, based on the feeling of no longer feeling welcome in social spaces due to the aging process. There is a loss of social roles, such as retirement before it is desired ${ }^{9}$. In this sense, elderly persons can experience a sense of uselessness and describe difficulties in not feeling more useful, due to the fact that they no longer work. In some cases this means finding it difficult to identify a reason to live ${ }^{13}$.

Accompanying retirement is the reduction in purchasing power, which constitutes financial loss. Financial problems can be categorized as not having enough money to live comfortably or for leisure activities $^{13}$.

The reduction in quality of life in a material sense is demonstrated by the loss of material goods, such as having to leave the house in which an elderly person has always lived because he or she can no longer live alone?

The reduction in cognitive sense is revealed by a decreased ability to respond to intellectual challenges. This even affects elderly persons without dementia, who reported realizing that their thinking is not agile as before and said they had greater difficulty to remember aspects of daily life? 
A cognition survey of 79 people between the ages of 56 and 89 in the USA attempted to test the hypothesis that the greater the executive functioning of a person, the greater the tolerance for death reminders; it was believed that people with lower executive functioning might not have the cognitive resources needed to implement changes aimed at more flexible strategies in response to reminders of death ${ }^{14}$.

The findings of the study found that executive function only influenced how reminders of death are dealt with by the elderly and not by younger people. Elderly persons and those with greater executive functioning responded to reminders of mortality with greater tolerance ${ }^{14}$.

Another study, however, found that elderly persons developed the desire to die due to a reduced quality of life as a consequence of aging and illness, as well as dependence, limitations in hearing and sight, among others ${ }^{13}$.

A survey of 16 centenarians in the UK also identified many losses experienced by elderly persons: from physical limitations, including gait and vision, to the death of loved ones and the lack of these people in their lives. On the other hand, in the present study, the participants were able to deal with their losses through the understanding that despite death, the loved one remains present in their life; and that although they have experienced the losses and tragic moments of two world wars, these people were able to recognize the beauty in their lives, with moments of joy, pleasurable activities and loved ones who lived and live throughout their lives ${ }^{15}$.

\section{Coping}

Coping, in the model by Lazarus and Folkman, is defined as the cognitive and behavioral actions and strategies used when faced with stressful situations arising from internal or external demands which are perceived as overburdening the personal resources of the individual ${ }^{5}$.

Coping is subdivided into two groups according to the function it performs: emotion-focused coping and problem-focused coping 5 .

On the other hand, Skinner et. al. suggests that the division between emotion-focused and problemfocused coping should no longer be used. Instead, these authors argue in favor of a hierarchical system of ways of acting which was constructed from the analysis of one hundred coping systems in which potential coping families were categorized (Chart 2$)^{16}$.

Chart 2. Synthesis of coping families according to study by Skinner; et. al. Portland, Oregon, 2003.

\begin{tabular}{|l|l|}
\hline Coping families & Components \\
\hline Problem solving & Developing strategy; instrumental action; planning \\
\hline Seeking information & Reading; observation; asking others. \\
\hline Inability to help oneself & Confusion; cognitive interference; cognitive exhaustion. \\
\hline Escape & Cognitive avoidance; behavioral avoidance; denial; illusory thinking. \\
\hline Self confidence & Emotional regulation; behavioral regulation; emotional expression; emotional approach. \\
\hline Seeking social support & Search for contact; search for comfort; instrumental help; spiritual support. \\
\hline Delegation & Seeks for maladaptive help; complaining; regret; feeling sorry for oneself. \\
\hline Isolation & Withdrawal from social life; concealment; avoiding other people. \\
\hline Accommodation & Distraction; cognitive restructuring; minimization; acceptance. \\
\hline Negotiation & Bargaining; persuasion; setting priorities. \\
\hline Submission & Rumination; rigid perseverance; intrusive thoughts. \\
\hline Opposition & Blame the other; projection; aggression. \\
\hline
\end{tabular}


A study conducted in 2014 used forms of coping classified according to Skinner's study and associated them with levels of subjective well-being. Subjective well-being was related to the different ways of coping with the losses related to aging ${ }^{9,16}$.

The search for social support as well as negotiation and accommodation were the coping strategies most associated with high levels of subjective well-being. On the other hand, the isolation, hopelessness, escape and submission coping strategies were associated with lower levels of subjective well-being ${ }^{9}$.

Coping can generate favorable or unfavorable results for health, as it consists of the actions taken to deal with a stressful situation that can either help or cause harmr ${ }^{4}$.

In the articles analyzed, some coping strategies may be considered unfavorable to health, such as anticipated mourning and the desire to die; evidenced in the speech of an eighty-six-year-old woman with a desire to die, in which she perceives death as representing the possibility of freedom from a meaningless and worthless life; although she also says she cannot kill herself and must wait for God's will. Thus, one notices the need to seek to repel the idea of suicide and support life in old age and in sickness ${ }^{10}$.

A study of thirty-one elderly people with the desire to die was carried out in the Netherlands to understand why some elderly people develop this feeling. Most participants had a moderate to strong desire to die. The elderly persons described the loss of a partner, work or independence and no longer feeling meaning or importance in their own lives, and reported that they were just waiting for their final moment ${ }^{13}$.

In a situation where one is simply waiting for death, social interaction, leaving the house and seeking entertainment become meaningless activities; favoring isolation, evidenced by the report of a 74-year-old woman who hardly left her house and no longer had an interest in talking to her relatives because she does not feel understood?

Hopelessness was also evidenced by a man of seventy-two who described feeling despair, anger, and no longer felt able to do some of his daily activities. Loneliness and a reduced sense of mastery over their own lives were also factors associated with the desire to die in the elderly ${ }^{13}$.

On the other hand, accommodation was an effective coping strategy associated with high levels of subjective well-being. This consists of using flexibility to adjust one's preferences to the available options. Accommodation was used by elderly people to adjust their goals and preferences by accepting and redefining a situation, as in the case of a female interviewee who described accepting Parkinson's disease and seeking to learn from it ${ }^{9,16}$.

When someone does not adjust their preferences to a new situation, but has their desires restrained by a context that prevents satisfaction, then the individual is using the coping strategy known as submission, which was associated with higher levels of subjective well-being in the study?

Negotiation is another coping strategy in which the individual seeks to adjust their preferences to the available options, but rather than accommodation, where the person yields their goals, in negotiation the individuals seeks alternatives to satisfy their goals and preferences. This strategy, when used by elderly people, was also associated with high levels of subjective well-being ${ }^{9}$.

On the other hand, a study conducted in Israel identified a reduction in subjective well-being in participants and found that the effect of the dying process is greater than aging itself. It is possible that at an advanced age of life, subjective well-being is less associated with chronological age and more associated with the still unexplained mechanisms of the dying process ${ }^{17}$.

In China, a survey of elderly persons in palliative care revealed the physical limitations that significantly affected the participants, who reported that they no longer felt able to enjoy food, engage in leisure activities, or maintain close relationships. However, despite these adversities, the participants reported dealing with a disease without a cure: living in the moment, maintaining normalcy and seeking spiritual comfort $^{12}$.

In terms of the recognition of their finitude, the elderly interviewed reported the need to maintain normality while facing a disease without a cure, 
the importance of living in the moment without worrying about the future, and the search for spiritual comfort through forgiveness, renouncing grudges and broadening their perspectives of life ${ }^{12}$.

In New Zealand, a longitudinal study of 25 elderly patients with severe heart disease which sought to follow the transition from independence to dependency and death identified the following results: for the participants, the transition was not a simple but a challenging and complex linear process. The losses during the transition were manifold: ranging from the loss of relationships with friends to hobbies and the loss of one's own home, as for some there was a need for a change of residence ${ }^{11}$.

Multiple losses, meanwhile, led some elderly people with severe heart disease to the desire to speed their deaths as they lost hope as they looked to the future and failed to find meaning or anything to look forward to. On the other hand, despite knowing that the end was near, others wanted to live and fulfill their desires and had the support of friends, family and the community. Faced with the uncertainty of death, some elderly persons opted to live by taking full advantage of each day as it comes ${ }^{11}$.

\section{REFERENCES}

1. Cavanaugh JC, Blanchard-Fields F. Adult development and aging. $6^{a}$ ed. USA: Cengage Learning; 2011.

2. Jaramillo IF, Fonnegra LJ. Los duelos en la vida. Colômbia: Grijalbo; 2015.

3. Farber SS. Envelhecimento e elaboração das perdas. Terc Idade Estud Envelhec [Internet]. 2012 [acesso em 13 jan. 2017];23(53):7-17. Disponível em: https:// www.sescsp.org.br/files/edicao_revista/cd42b4197df9-4182-8a57-4188279cf8a5.pdf

4. Nolen-Hoeksema S, Fredrickson BL, Loftus GR, Lutz C. Atkinson \& Hilgard's introduction to psychology. $16^{\mathrm{a}}$ ed. [New Delhi]: Cengage Learning; 2015.

5. Lazarus RS, Folkman S. Stress, appraisal and coping. New York: Springer Publishing Company; 1984.

6. Rodrigues FSS, Polidori MM. Enfrentamento e resiliência de pacientes em tratamento quimioterápico e seus familiares. Rev Bras Cancerol. 2012;58(4):619-27.

\section{CONCLUSION}

Aging leads to the accumulation of losses, which means symbolic deaths through the loss of physical vigor, loved ones, the strength of emotional relationships and a social life and also one's value as a person in a society based on productivity.

The synthesis of the analyzed studies indicates that when faced with aging and death, whether it is a symbolic death or the perception of their own finitude, the elderly used a coping strategy with favorable and unfavorable results for health. The favorable strategies were: negotiation, acceptance, accommodation, the search for social support, the search for spiritual comfort and living in the moment; while the unfavorable strategies were: anticipated mourning, a desire to die, isolation and submission.

Thus, it can be said that while some elderly people faced aging and finitude with anticipated mourning and the desire to die, due to the fear of dependency and of becoming a burden for relatives; others faced aging, loss, and finitude by seeking spiritual comfort, social support, and acceptance.

7. Souza MT, Silva MD, Carvalho R. Integrative review: what is it? How to do it? Einstein. 2010;8(1):102-6.

8. Sinclair S, Beamer K, Hack TF, McClement S, Bouchal SR, Chochinov HM, et al. Sympathy, empathy, and compassion: a grounded theory study of palliative care patients' understandings, experiences, and preferences. Palliat Med. 2016:1-11.

9. Dockendorff DCT. Healthy ways of coping with losses related to the aging process. Educ Gerontol. 2014;40(5):363-84.

10. Giacomin KC, Santos WJ, Firmo JOA. O luto antecipado diante da consciência da finitude: a vida entre os medos de não dar conta, de dar trabalho e de morrer. Ciênc Saúde Coletiva. 2013;18(9):2487-96.

11. Waterworth S, Jorgensen D. It's not just about heart failure: voices of older people in transition to dependence and death. Health Soc Care Community. 2010;18(2):199-207. 
12. Ho AH, Chan CL, Leung PP, Chochinov HM, Neimeyer RA, Pang SM, et al. Living and dying with dignity in Chinese society: perspectives of older palliative care patients in Hong Kong. Age Ageing. 2013;42(4):455-61.

13. Rurup ML, Deeg DJ, Poppelaars JL, Kerkhof AJ, Onwuteaka-Philipsen BD. Wishes to die in older people: a quantitative study of prevalence and associated factors. Crisis. 2011;32(4):194-203.

14. Maxfield M, Pyszczynski T, Greenberg J, Pepin $\mathrm{R}, \mathrm{Davis}$ HP. The moderating role of executive functioning in older adults' responses to a reminder of mortality. Psychol Aging. 2012;27(1):256-63.
15. Hutnik N, Smith P, Koch T. What does it feel like to be 100 ? Socio-emotional aspects of well-being in the stories of 16 Centenarians living in the United Kingdom. Aging Ment Health. 2012;16(7):811-8.

16. Skinner EA, Edge K, Altman J, Sherwood H. Searching for the structure of coping: a review and critique of category systems for classifying ways of coping. Psychol Bull. 2003;129(2):216-69.

17. Palgi Y, Shrira A, Ben-Ezra M, Spalter T, Shmotkin $\mathrm{D}$, Kavé G. Delineating terminal change in subjective well-being and subjective health. J Gerontol Ser B Psychol Sci Soc Sci. 2010;65(1):61-4.

Received: June 13, 2017

Reviewed: September 14, 2017

Accepted: October 02, 2017 